\title{
A Planar UWB Antenna with Dual Band Rejection Capability Using Double Rotated ESRRs
}

\author{
Ahmed S. Elkorany ${ }^{1 *}$, Ghidaa T. Ahmed ${ }^{1}$, Demyana A. Saleeb ${ }^{2}$ \\ ${ }^{1}$ Dept. of Electronics and Electrical Comm. Eng., Faculty of Electronic Engineering, Menoufia University, Menouf, \\ 32952, Egypt \\ ${ }^{2}$ Faculty of Engineering, Kafr ElShiekh University, Egypt \\ *corresponding author, E-mail: elkoranyahmed@yahoo.com
}

\begin{abstract}
In this paper, CPW-Fed ultra wideband (UWB) planar monopole antenna (PMA) loaded by double elliptical split ring resonators (ESRRs) for double band-notch characteristics is introduced and examined. Two different ESRRs with different dimensions are printed in the antenna backside to notch two different frequencies. The ESRRs are also rotated and the corresponding return loss effect is examined. Different notch frequencies can be obtained by varying the ESRRs, dimensions. Two single SRRs are used to notch two frequencies instead of using dual SRR pairs. Two notch frequencies at $5.2 \mathrm{GHz}$ and $6.9 \mathrm{GHz}$ has been obtained to notch WLAN and C-band wireless applications, respectively. A directive radiation pattern in E-plane and omnidirectional radiation patterns in the H-plane could be observed. Also the gain is suppressed in the notch frequencies. The group delay is nearly stable in the UWB frequency range, except at the notch frequencies, which is distorted sharply. So, the proposed antenna is a good candidate for the modern UWB systems. Finite element method FEM and finite integration technique FIT are used to simulate the proposed structures through the usage of Ansys HFSS and CST MWS. Very good agreement between both results has been obtained.
\end{abstract}

Keywords- UWB antenna; CPW; Notch frequency; Elliptical SRR; Rotated; FEM; HFSS and CST.

\section{Introduction}

A leap in scientific research has occurred since February 2002, when the FCC issued a ruling that UWB could be used for data communications as well as for radar and safety applications [1]. The FCC allowed the frequency band between 3.1 and $10.6 \mathrm{GHz}$ for Ultra-wideband transmission. Higher data rates, saturation of the frequency spectrum, low power consumption, etc. are some of the reasons why Ultrawideband has been of increased interest over the past years [2]. UWB system has features of low cost and low complexity as it based on baseband signal transmission. Sometimes, UWB planar antennas with frequency notch characteristics are designed to to suppress coexistence narrow-band systems and services like WLAN, WiMAX, c-, and $\mathrm{x}$-band wireless systems [3, 4]. These frequency bands could be rejected with band stop filters, but this approach would increase the system complexity [5]. So it is necessary to design the UWB antenna with band notched characteristic with reduced complexity and cost. The band notch characteristics can be obtained through different slots in radiated patch [6], fed line [7], slots in ground [8], and also parasitic patch [9]. Also a notch can be obtained using a quasi- complementary split ring resonator (CSRR) in fed line [10-16] or EBG structure etching on patch/ground plane [17].

In this paper, CPW-Fed UWB planar monopole antenna loaded by two ESRRs for dual notch frequencies is introduced and examined. A single ESRR with specific dimensions is loaded in the antenna backside to stop single frequency instead of using a pair of SRRs as in [9]. Also dual notch frequencies could be obtained using dual SRRs instead of using dual SRR pairs, as in [18]. The ESRRs dimensions and/or positions are changed and the corresponding return loss effect is presented. Also the ESRRs are rotated and the resultant effect is stored. Different notch frequencies could be obtained through different ESRR dimensions. A $5.2 \mathrm{GHz}$ and 6.9 $\mathrm{GHz}$ notch frequencies can be obtained using two different ESRRs, to reject WLAN [19] and C-band wireless systems [20], respectively. A directive radiation pattern in Eplane and nearly omnidirectional pattern in H-plane are obtained. Also the gain is suppressed in the notch frequencies. The group delay is nearly stable in the UWB frequency range, except at the notch frequencies, which is distorted sharply. FEM and FIT are utilized to simulate the proposed antenna structure using Ansys HFSS [21], and CST MWS [22] respectively.

\section{Antenna design}

The proposed UWB antenna configuration is shown in Fig. $1-a$. The proposed antenna is printed on duriod dielectric substrate having thickness of $1.6 \mathrm{~mm}$ and relative permittivity 2.2. The elliptical monopole antenna having major radius $r$ and $r_{a}$ is the ratio of minor to major radii. The antenna is fed with a coplanar waveguide. The ground planes widths are $\mathrm{W}_{1}$ and $\mathrm{W}_{2}$, and their length is $\mathrm{L}_{\mathrm{s}}$. The microstrip line width is $\mathrm{S}$ .The slots between the ground planes and signal line have width $S_{g}$. Table 1 shows the design parameters used for the prototype. Figure 1-b shows the ESRR structure. It consists of two elliptical rings with major radius a, the ratio between minor and major axis is $r_{s}$, the metal width is $c$ and the spacing between the two rings is $d$. there are two gaps $g_{1}$ and $\mathrm{g}_{2}$. 


\section{Results and discussions}

The effect of ESRR dimensions on its resonant frequency is shown in Fig. 2. A lot of dimension combinations are tested to investigate their effects. Some of these cases and the resultant resonant frequency are shown in table 2. As shown, by adjusting the ESRR dimensions, any notch frequency can be obtained through the entire UWB frequency band.

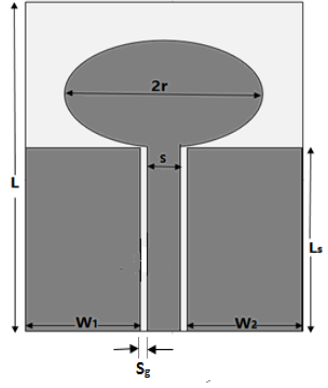

(a)
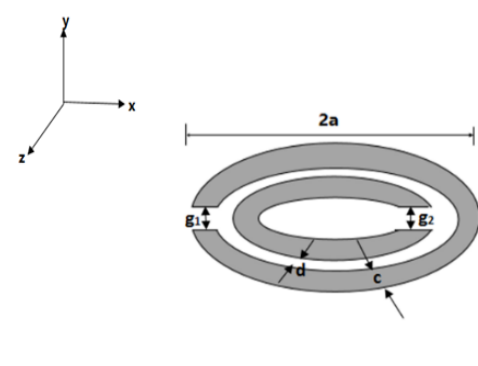

(b)
Figure 1: (a) CPW UWB elliptical planar monopole antenna and (b) ESRR structure.

Table 1: The design parameters of the proposed antenna

\begin{tabular}{cc}
\hline Design parameter & Dimensions in $(\mathbf{m m})$ \\
\hline $\mathbf{L}$ & 60 \\
\hline $\mathbf{W}_{\mathbf{1}}=\mathbf{W}_{\mathbf{2}}$ & 22.5 \\
\hline $\mathbf{r}$ & 18.859 \\
\hline $\mathbf{r}_{\mathbf{a}}$ & 0.6 \\
\hline $\mathbf{S}$ & 5 \\
\hline $\mathbf{L}_{\mathbf{s}}$ & 23.5 \\
\hline $\mathbf{S}_{\mathbf{g}}$ & 0.5 \\
\hline
\end{tabular}

Table 2: Resonant frequencies of ESRRs for different a, $\mathrm{c}$ and $r_{s}$ values.

\begin{tabular}{|c|c|c|c|c|}
\hline \multicolumn{4}{|c|}{ SRR dimensions(mm) } & \multirow{3}{*}{$\begin{array}{c}\begin{array}{c}\text { Resonant } \\
\text { frequency }(\mathbf{G H z})\end{array} \\
9.5\end{array}$} \\
\hline & & C & $\mathbf{r}_{\mathrm{s}}$ & \\
\hline ESRR1 & 2.2 & 0.4 & 0.5 & \\
\hline ESRR2 & 2.6 & 0.4 & 0.65 & 6.95 \\
\hline ESRR3 & 3 & 0.4 & 0.4 & 6.4 \\
\hline ESRR4 & 3.5 & 0.5 & 0.5 & 5.12 \\
\hline ESRR5 & 4 & 0.5 & 0.4 & 4.4 \\
\hline
\end{tabular}

3.1 Single Band-Notched UWB Antenna Results and Discussion
To design UWB antenna with single notch frequency, single ESRR is placed on the antenna backside. This notch frequency can be determined by the SRR geometrical dimensions. The antenna structure with ESRR loading is shown in Fig. 3. In the beginning, only single ESRR is printed on the antenna backside. Figures 4 and 5 show the return loss versus frequency using two different cases from table 2. Also the ESRR position effect is studied. Table 3 and Table 4 shows the different ESRR2 and ESRR4 positions respectively. Figure 4 shows the loading effect of ESRR2 on the return loss at different ESRR2 positions. A notch frequency at $6.9 \mathrm{GHz}$ is obtained when ESRR2 placed at position 2. A notch frequency at $5.1 \mathrm{GHz}$ is obtained when ESRR4 is placed at position 1 on the UWB antenna as shown in Fig. 5.

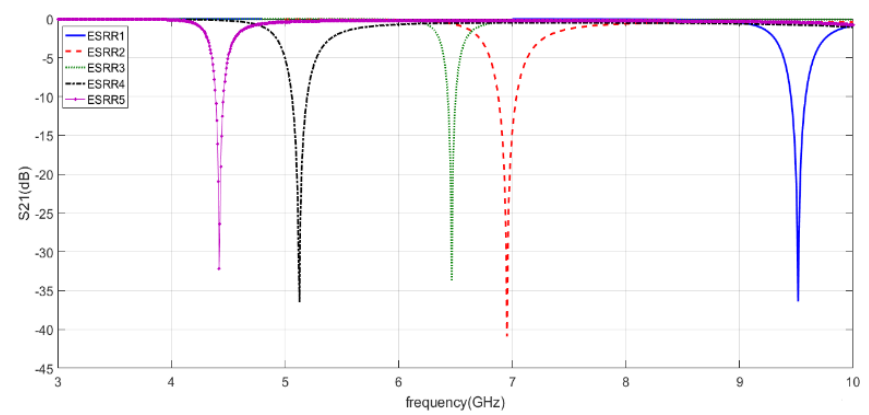

Figure 2: Simulated $S_{21}$ of the different geometrical dimensions of ESRR Using HFSS.

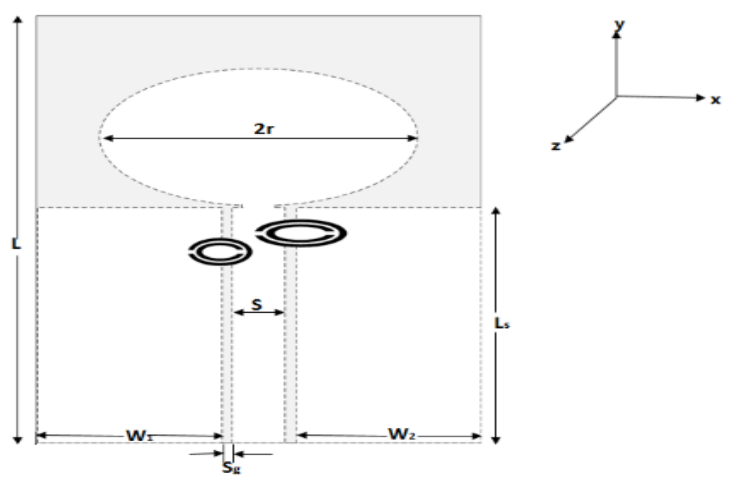

Figure 3: The proposed antenna with two different ESRRs.

Table 3: Different ESRR2 positions

\begin{tabular}{cc}
\hline Positon NO & $\begin{array}{c}\text { Y axis values } \\
\text { in } \mathbf{~ m m}\end{array}$ \\
\hline $\mathbf{1}$ & -4 \\
\hline $\mathbf{2}$ & -5 \\
\hline $\mathbf{3}$ & -7 \\
\hline $\mathbf{4}$ & -10 \\
\hline $\mathbf{5}$ & -12
\end{tabular}




\subsection{Dual Band-Notched UWB Antenna Results and Discussion}

UWB antenna with two notch frequencies can be obtained by loading the antenna with two different ESRRs. As shown in table 2 four different ESRRs are examined. Two of these ESRRs will be printed on the antenna backside. Table 5 shows the different position combinations of the two ESRRs. Figure 6 shows the return loss versus frequency for these combinations. As shown in Fig. 6, by loading the antenna with two different ESRRs two different notch frequencies can be obtained. The notch frequencies of each ESRRs is shifted compared to the single ESRR cases. This is done due to the mutual coupling effect between the two ESRRs.

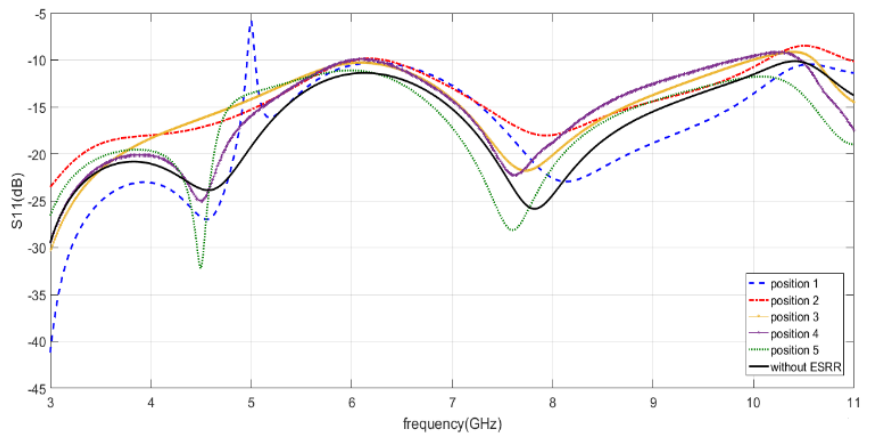

Figure 4: Simulated S11 characteristics of the UWB antenna with ESRR2 only using HFSS.

\begin{tabular}{cc}
\hline Positon NO & $\begin{array}{c}\text { Y axis values in } \\
\text { mm }\end{array}$ \\
\hline $\mathbf{1}$ & -3.5 \\
\hline $\mathbf{2}$ & -6.8 \\
\hline $\mathbf{3}$ & -9 \\
\hline $\mathbf{4}$ & -10 \\
\hline $\mathbf{5}$ & -12 \\
\hline
\end{tabular}

Table 4:

Different

ESRR4

positions

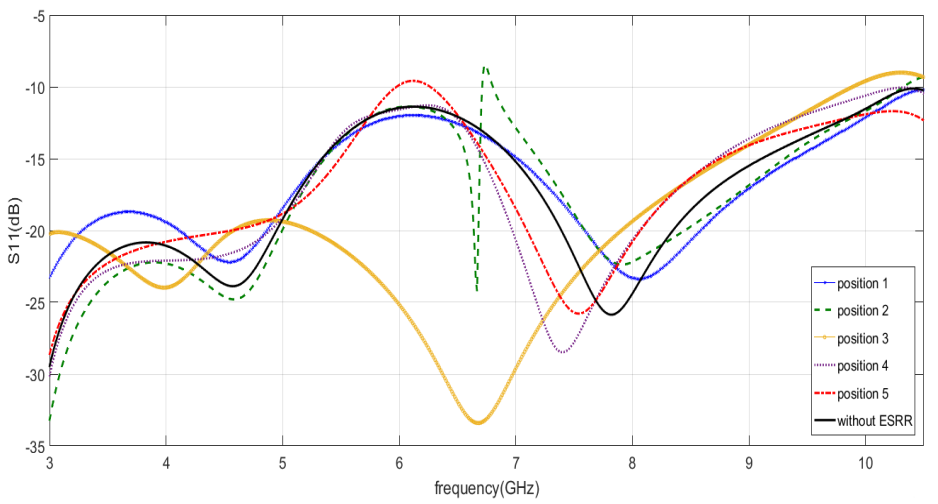

Figure 5: Simulated S11 characteristics of the UWB antenna with ESRR4 only using HFSS.

\subsection{Double ESRRs Rotation effect}

Figure 7 shows the UWB antenna with two rotated ESRRs. The two ESRRs are rotated and the $S_{11}$ results is also recorded in Fig 8. As shown in Figure 8 rotating the ESRRs increases or decreases the coupling between them and hence changes the resultant notch frequencies. ESRR4 with rotational angle $\theta_{1}$ and ESRR2 with rotational angle $\theta_{2}$ are placed symmetrical at antenna backside as shown in Figure 7. ESRR4 is rotated clockwise direction and ESRR2 is rotated anticlockwise direction. The effect of changing two rotational angle $\theta_{1}, \theta_{2}$ of Elliptical SRRs on the notch frequency is shown in figure 8 and we note that when the two angles changed by the same degree but in opposite directions and there is $180^{\circ}$ phase shift between them the notch frequency almost does not change. Figure 9 shows the comparison between HFSS and CST simulated $S_{11}$ results. Very good agreement has been obtained between them.

Table 5: The different ESRR combinations and positions, values are in $\mathrm{mm}$.

\begin{tabular}{ccccc}
\hline Case NO & \multicolumn{2}{c}{ Right ESRR } & \multicolumn{2}{c}{ Left ESRR } \\
\hline $\mathbf{1}$ & ESRR4 & $\mathrm{y}=-4.5$ & ESRR2 & $\mathrm{y}=-3.7$ \\
\hline $\mathbf{2}$ & ESRR2 & $\mathrm{y}=-4.5$ & ESRR1 & $\mathrm{y}=-3.5$ \\
\hline $\mathbf{3}$ & ESRR2 & $\mathrm{y}=-4.5$ & ESRR3 & $\mathrm{y}=-6$ \\
\hline
\end{tabular}

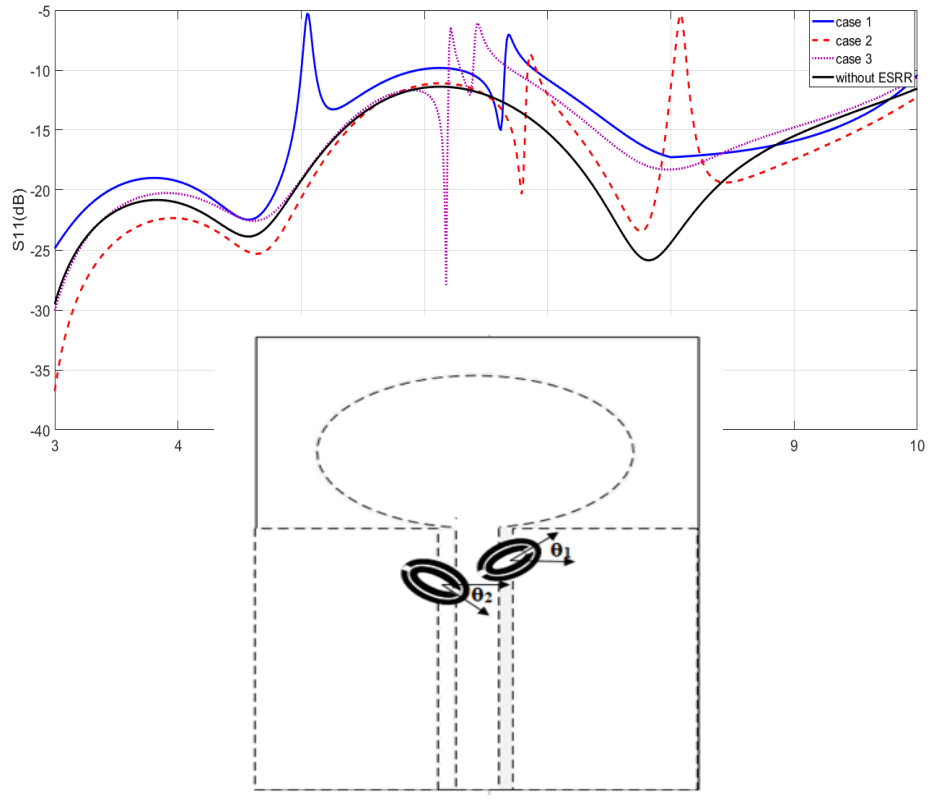

Figure 7: The UWB antenna with two rotated ESRRs with different rotational angles $\theta_{1}, \theta_{2}$ 


\subsection{Radiation patterns, gain and efficiency}

Figure 10 shows the different radiation pattern planes at different frequencies 4,6 , and $10 \mathrm{GHz}$ for the proposed antenna with ESRR2 and ESRR4 at rotational angles $\theta_{1}$ and $\theta_{2}$ respectively. From figure, it is clear that the pattern is directive in the E- plane and omnidirectional pattern in the $\mathrm{H}$ plane which makes it a good candidate for UWB devices.

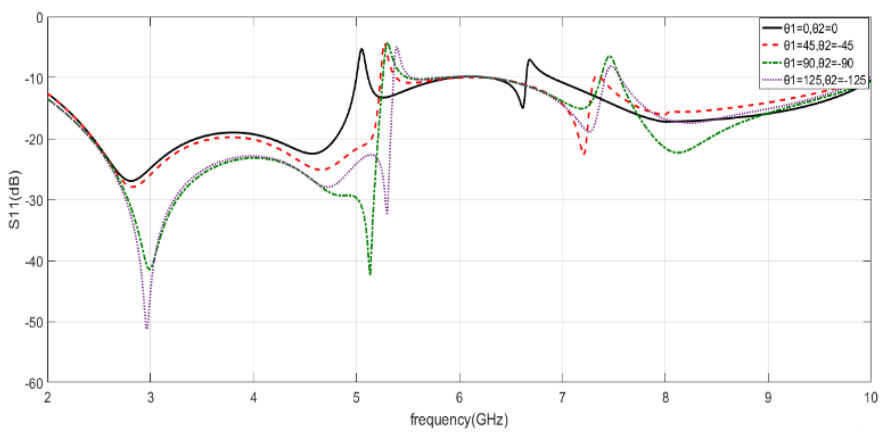

Figure 8: Simulated $S_{11}$ characteristics of proposed antenna loaded with ESRR2 and ESRR4 for various rotation angles.

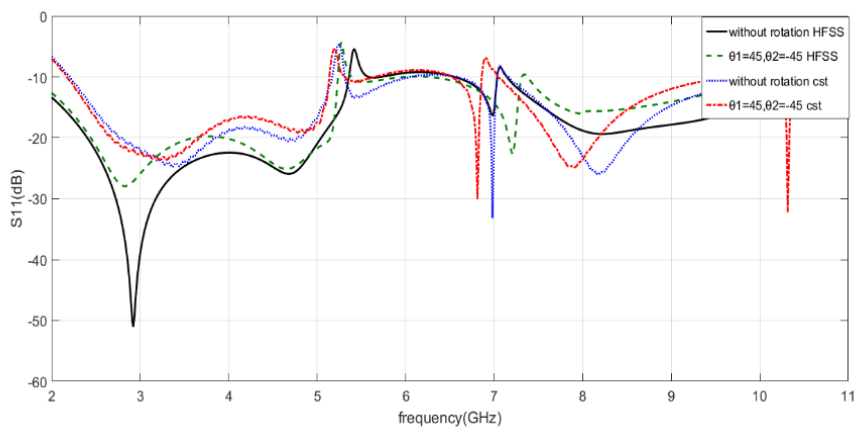

Figure 9: HFSS and CST Simulated $S_{11}$ characteristics of proposed antenna loaded with double rotational ESRRs and with non-rotational ESRRs

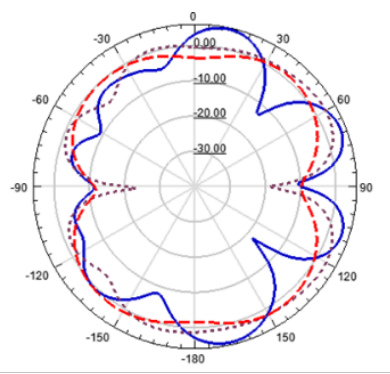

(a)

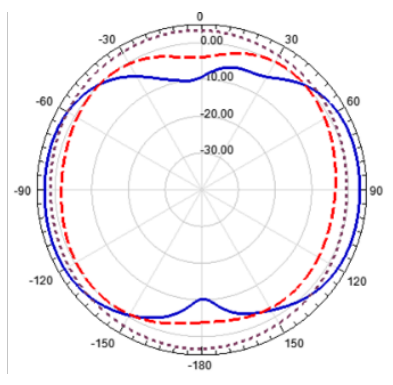

(b)
Figure 10: The Radiation patterns of the UWB antenna loaded with ESRR4 and ESRR2 at angles $\theta_{1}=45^{\circ}$ and $\theta_{2}=-45^{\circ}$ respectively (a) E-plane (b) H- plane [at different frequencies $4 \mathrm{GHz}$ (long dashes), $6 \mathrm{GHz}$ (short dashes), and $10 \mathrm{GHz}$ (solid)]
Figure 11 shows the peak gain of the proposed antenna. The simulated peak gain ranges from 1.5 to $5 \mathrm{~dB}$ throughout the whole UWB frequency band, except double stopband in the case of loading ESRR2 and ESRR4. As discussed above, the gain is suppressed in the notch frequencies. Thus, the peak gain decreases sharply at $5.2 \mathrm{GHz}$ and $6.9 \mathrm{GHz}$, which clearly indicates the dual band rejection functions of the proposed antenna. High radiation efficiency for the antenna is the main required parameter in UWB system, which means that all type of losses, including dielectric and return loss should be kept very low. The proposed antenna structure offers high radiation efficiency of more than $95 \%$ throughout the working band as shown in Fig.11. The antenna radiation efficiency significantly decreases over these two bandnotched frequencies. The group delay is shown in Fig. 12. The group delay is almost stable across the operating band, but at the notch frequencies 5.2 and $6.9 \mathrm{GHz}$ the group delay has very sharp changes.

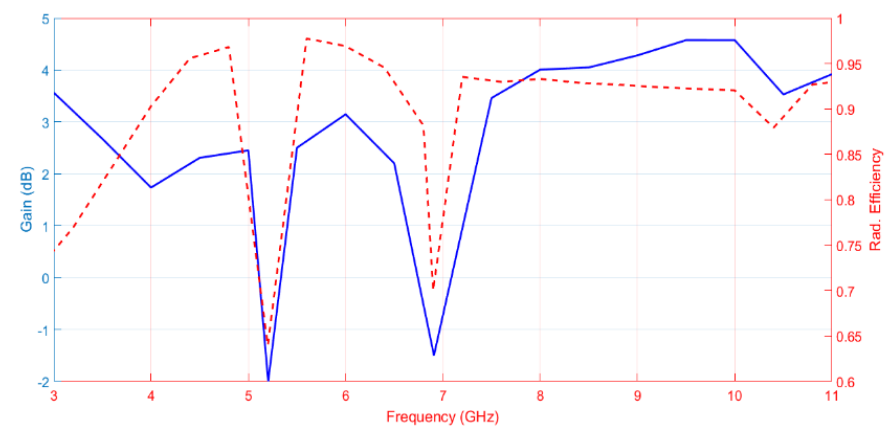

Figure 11: The gain and radiation efficiency versus frequency for the antenna with two HSRRs ESRR4 and ESRR2 with rotational angles $\theta_{1}=45^{\circ}$ and $\theta_{2}=-45^{\circ}$ respectively

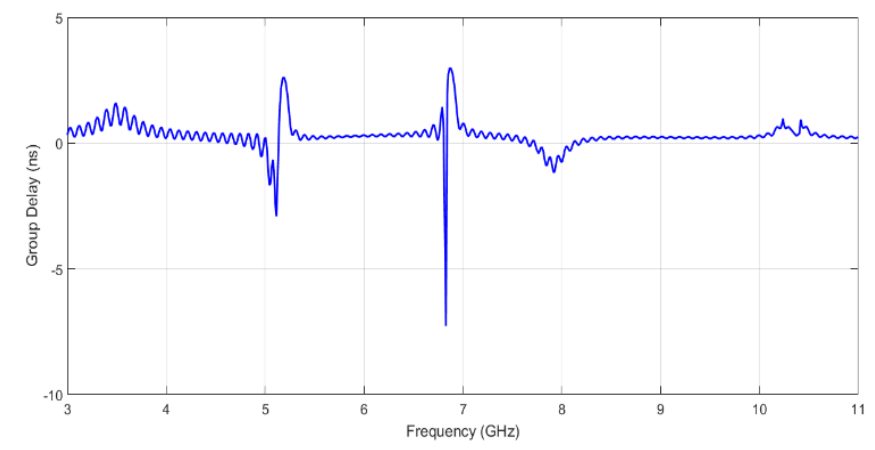

Figure 12: The group delay of propose antenna with two HSRRs ESRR4 and ESRR2 with rotational angles $\theta_{1}=45^{\circ}$ and $\theta_{2}=-45^{\circ}$ respectively

\section{Conclusion}

The design of CPW UWB elliptical planar monopole antenna loaded with elliptical split ring resonators (ESRRs) to obtain frequency notch characteristics is proposed. Notch frequency can be obtained by the electromagnetic coupling of the ESRR with the CPW. Single ESRR is loaded in the antenna backside 
for single notch frequency. By loading two different ESRRs in the antenna backside, two different notch frequencies can be obtained. ESRR dimensions can be adapted to resonate in any frequency along the UWB frequency band. The ESRR dimensions and position effect on the notch frequency is investigated. The proposed antenna loaded double ESRRs (ESRR2, ESRR4) with rotational angles $\theta_{1}$ and $\theta_{2}$ respectively yields directive pattern in the E- plane and omnidirectional pattern in H- plane. Also in both cases the gain is suppressed in the notch frequencies. FEM and FIT are used simulate the proposed antenna structure through HFSS and CST MWS respectively. A prototype of the proposed antenna is fabricated and the return loss is measured and compared to the simulated $S_{11}$ results. Very good agreement between them has been obtained. The group delay is nearly stable in the UWB frequency range, except at the notch frequencies, which is distorted sharply. So, the proposed antenna is a good candidate for the modern UWB systems.

\section{References}

[1] Federal Communications Commission. Revision of Part 15 of the Commission's Rules Regarding Ultra-Wideband Transmission Systems, First Report and Order, FCC 02, vol. 48, pp. 1-89, 2002.

[2] I. Oppermann, M. Hamalainen and J. Iinatti, UWB Theory and Applications, John Wiley \& Sons, Ltd, 2004.

[3] W. Choi, K. Chung, J. Jung and J. Choi, Compact ultrawideband printed antenna with band-rejection characteristic, IEE Electronics Letters, vol.41, no. 18, pp. 990-991, 1st September, 2005.

[4] Ehab K. I. Hamad and Nirmen Mahmoud, Compact TriBand Notched Characteristics UWB Antenna for WiMAX, WLAN and X-Band Applications, advanced electromagnetics, vol. 6, no. 2, May 2017.

[5] Awida M., Boutejdar A., Safwat A., El-Hennawy H.and Omar A, Multi-Bandpass Filters Using Multi-Armed Open Loop Resonators with Direct Feed, IEEE/MTT-S Int. Microwave Symposium, Honolulu, HI, pp. 913 - 916, 2007.

[6] Sai K. Venkata, Muktikanta Rana, Pritam S. Bakariya, Santanu Dwari and Manas Sarkar, Planar Ultrawideband Monopole Antenna with Tri-Notch Band Characteris-tics, Progress In Electromagnetics Research C, vol.46, pp.163-170, 2014.

[7] Y. Zhang, W. Hong, C. Yu, Z.Q. Kuai, Y.D. Don and J.Y. Zhou, Planar Ultrawideband Antennas with Multiple Notched Bands Based on Etched Slots on The Patch and/or Split Ring Resonators on The Feed Line, IEEE Trans. Antennas Propag., vol. 56, pp. 3063-3068, 2008.

[8] S. R. Branch, Band-notched elliptical slot UWB microstrip antenna with elliptical stub filled by the $\mathrm{H}$-shaped slot, J. Electromagn. Waves Appl., vol. 22, pp. 1993-2002, 2008 .

[9] J. Y. Sidiqui, C. Saha, and Yahia M.M. Antar, Compact SRR loaded UWB Circular Monopole Antenna with Frequency Notch Characteristics, IEEE Trans. Antennas Propag., vol 62, no.8. pp. 4015-4020, 2014.

[10] Zhan K, Guo Q, Huang K, A miniature planar antenna for Bluetooth and UWB applications, J. Electromagn. Waves Appl., vol. 24, pp. 2299-2308, 2010.

[11] W. T. Li, Y.Q. Hei, W. Feng, Planar Antenna for 3G/Bluetooth/WIMAX and UWB Applications with Dual Band Notched Characteristics, IEEE Antennas Wireless Propag. Lett, vol.11, pp. 61-64, 2012.

[12] X.J Liao., H.C Yang, N. Han, and Y. Li, Y.H. Sun, UWB antenna with dual narrow band notches for lower and upper WLAN bands, Electron. Lett. vol. 46, pp. 1593-1594, 2010.

[13] L. Li, Z.L. Zhou, J. S. Hong, and B.Z.Wang, Y.H. Sun, Compact dual- band-notched UWB planar monopole antenna with modified SRR, Electron. Lett. vol. 47, No.17, pp. 950 951, 2011.

[14] D. Jiang, Y. Xu, R. Xu and W. Lin, Compact dual-bandnotched UWB planar monopole antenna with modified CSRR, Electron. Lett. vol. 48, No.20, Sep 2012.

[15] W. Jiang and W. Che , A novel UWB antenna with dual notched bands for WiMAX and WLAN applications, IEEE Antennas Wireless Propag. Lett. vol. 11, pp. 293-296, 2012.

[16] M.-C. Tang, S. Xiao, T. Deng, D. Wang, J. Guan, B. Wang, and G.-D. Ge, Compact UWB antenna with multiple band-notches for WiMAX and WLAN, IEEE Trans. Antennas Propag., vol. 59, no. 4, pp. 1372-1376, April 2011.

[17] Lin Peng and Cheng-Li Ruan, UWB Band-Notched Monopole Antenna Design Using Electromagnetic-Bandgap Structures, IEEE transactions on microwave theory and techniques, vol. 59, no. 4, 2011.

[18] J. Y. Sidiqui, C. Saha, Yahia M.M. Antar, Compact Dual SRR Loaded UWB Monopole Antenna with Dual Frequency and Wideband Notch Characteristics, IEEE Antennas and Wireless Propag. Lett, vol.14, pp 100-103, 2014.

[19] P. Kumar J. L. Masa-Campos, Dual Polarized Monopole Patch Antennas for UWB Applications with Elimination of WLAN Signals, advanced electromagnetics, vol.5, no.1, 2016.

[20] Abhik Gorai, Anirban Karmakar, Manimala Pal and Rowdra Ghatak, Multiple fractal-shaped slots-based UWB antenna with triple-band notch functionality, Journal of 
ADVANCED ELECTROMAGNETICS, VOL. 7, NO. 1, JANUARY 2018

Electromagnetic Waves and Applications, vol. 27, no. 18, pp.

2407-2415, 2013.

[21]http://www.ansys.com/Products/Electronics/ANSYS-

HFSS

[22] https://www.cst.com/products/cstmws 